\title{
On the method of improving sustainable development of railway transportation of cargoes in containers
}

\author{
Andrey Gordienko*, and Oksana Molchanova \\ Ural State University of Railway Transport, Kolmogorov St., 60, 620034 Yekaterinburg, Russia
}

\begin{abstract}
For railway transportation of cargoes, the consignors often face the necessity in development of the placement and securing methods that require design-basis justification. The applicable regulatory documents in the field of placement and securing of cargoes in the railway transport provide no method for calculation of methods for the placement and securing of cargoes in containers, although the method to justify the placement and securing of the container in the wagon is established. The absence of the approved method causes difficulties for consignors in choosing rational methods for the placement and securing of cargoes in containers and, of course, affects the sustainable development of railway transportation in containers and the transportation safety. This work is aimed at creating the method for determining the inertia forces acting on cargoes in containers during railway transportation, a well as design-basis justification of loads acting from cargo on container elements.
\end{abstract}

\section{Introduction}

The Russian Railways continues paying particular attention to the sustainable development of transportation in containers [1].

Currently, Chapter 12 of the Technical conditions for the placement and securing of goods in wagons and containers TU TSM-943 dated 27/05/2003 should be followed for the placement and securing of goods in containers [2] (hereinafter - TU TSM-943). At this, the containers are often loaded according to the provisions of Chapter 12 of TU TSM-943 [2] or the sketches when the method of the placement and securing of cargoes is provided in TU TSM-943 but there is no scheme of specific typical size [2].

However, due to high demand in shipment in containers of a wide range of cargoes, it is not always possible to perform loading according to the specific clause of Technical Conditions and the sketch. The consignors face the necessity in development of the methods of placement and securing that are not provided for in the Technical Conditions and require design-basis justification.

The analysis of the applicable regulatory documents in the field of placement and securing of cargoes in the railway transport $[2,3]$ shows that they provide no methods for placement and securing of cargoes in containers. Also it should be noted that according to

\footnotetext{
* Corresponding author: gordiii89@yandex.ru
} 
the method provided in the Technical Conditions, it is possible to make justification of placement and securing of container on the wagon but not of cargo in the container.

The absence of the approved method causes difficulties for consignors in choosing rational methods for the placement and securing of cargoes in containers and, of course, affects the sustainable development of railway transportation in containers.

In addition, the statistics of events not related to the violated safe movement of trains shows that there occurred falling of cargo out of containers in the rail net due to high inertia forces appearing in transit from cargoes and acting on the container end door and that were not assessed during loading design.

Therefore, this article has the task to develop the method for determining the inertia forces acting on cargoes in containers during railway transportation, a well as design-basis justification of loads acting from cargo on container elements.

\section{Materials and methods}

The problems of development of transportation in containers have been studied in a great deal of works $[4,5]$. There are insufficient articles describing the issues of placement and securing of containers on wagons and cargoes in containers [6].

To solve the tasks set forth in the work, the works in the field of placement and securing of cargoes in wagons and containers were used [7,8].

The analytical research is based on the fundamental principles of theoretical mechanics, as well as on the analysis of the Russian and international standards, recommendations. To test the formalized method, the software package MathCAD was used.

\section{Results and Discussion}

It is known [9] that freight container means a unit of transport equipment having:

- a constant technical characteristic to ensure strength for repeated use (during the established service life, if any);

- a special design to ensure cargo transportation by one or several kinds of transport in the direct and mixed traffic without cargoes transshipment;

- appliances to ensure mechanical transshipment from one kind of transport to the other;

- a design to ensure easy cargo handling;

- internal volume equal to 1 cub. $m$ and more.

The general purpose (universal) freight containers with rigid side and end walls and floor, as well as the door in the one end wall at least, intended for cargo transportation and temporary storage, requiring no temperature adjustment, except for liquids, gases, dry bulk cargoes, cars and cattle, have become most widely used. The requirements for them are set forth by ISO 1496-1:2013 Series 1 freight containers - Specification and testingPart 1: General cargo containers for general purposes [10].

The main types of the universal multi-tonnage containers transported by the railway are given in Table 1 as per [10]. 
Table 1. Main types of the universal multi-tonnage containers transported by the railway and their characteristics.

\begin{tabular}{|c|c|c|c|c|c|}
\hline \multirow{2}{*}{$\begin{array}{l}\text { Designation of } \\
\text { freight } \\
\text { container }\end{array}$} & \multicolumn{2}{|c|}{ Maximum length } & \multirow{2}{*}{$\begin{array}{c}\text { Length by } \\
\text { exposed faces } \\
\text { of the end } \\
\text { angle fittings, } \\
\text { mm }\end{array}$} & \multirow{2}{*}{$\begin{array}{c}\text { Maximum } \\
\text { gross } \\
\text { weight, } \mathrm{kg}\end{array}$} & \multirow{2}{*}{$\begin{array}{l}\text { Number of } \\
\text { lading } \\
\text { anchors in the } \\
\text { container } \\
\text { base, pcs. }\end{array}$} \\
\hline & feet & $\mathbf{m}$ & & & \\
\hline (1) & $(2)$ & (3) & (4) & (5) & (6) \\
\hline$\frac{1 \mathrm{EEE}}{1 \mathrm{EE}}$ & $45(40)^{*}$ & $13.7(12.2)^{*}$ & $\begin{array}{c}13716 \\
(12192)^{*}\end{array}$ & 30480 & 16 \\
\hline $1 \mathrm{AAA}$ & \multirow[t]{2}{*}{40} & \multirow[t]{2}{*}{12.2} & \multirow[t]{2}{*}{12192} & \multirow[t]{2}{*}{30480} & \multirow[t]{2}{*}{16} \\
\hline \begin{tabular}{|c|}
$1 \mathrm{AA}$ \\
$1 \mathrm{~A}$ \\
$1 \mathrm{AX}$
\end{tabular} & & & & & \\
\hline $1 \mathrm{BBB}$ & \multirow[t]{4}{*}{30} & \multirow[t]{4}{*}{9.1} & \multirow[t]{4}{*}{9125} & \multirow[t]{4}{*}{30480} & \multirow[t]{4}{*}{12} \\
\hline $1 \mathrm{BB}$ & & & & & \\
\hline 1B & & & & & \\
\hline $1 \mathrm{BX}$ & & & & & \\
\hline $1 \mathrm{CC}$ & \multirow[t]{3}{*}{20} & \multirow[t]{3}{*}{6.0} & \multirow[t]{3}{*}{6058} & \multirow[t]{3}{*}{30480} & \multirow[t]{3}{*}{10} \\
\hline $1 \mathrm{C}$ & & & & & \\
\hline $1 \mathrm{CX}$ & & & & & \\
\hline $1 \mathrm{D}$ & \multirow[t]{2}{*}{10} & \multirow[t]{2}{*}{3.0} & \multirow[t]{2}{*}{2991} & \multirow[t]{2}{*}{10160} & \multirow[t]{2}{*}{8} \\
\hline $1 \mathrm{DX}$ & & & & & \\
\hline
\end{tabular}

* the lengths by exposed faces of fittings used for installation on the platform are given in brackets

Let's consider the design elements of the universal containers designed for compensation of inertia loads appearing during cargo transportation (Figure 1). The end and side walls, as well as lading anchors are determining in this aspect.

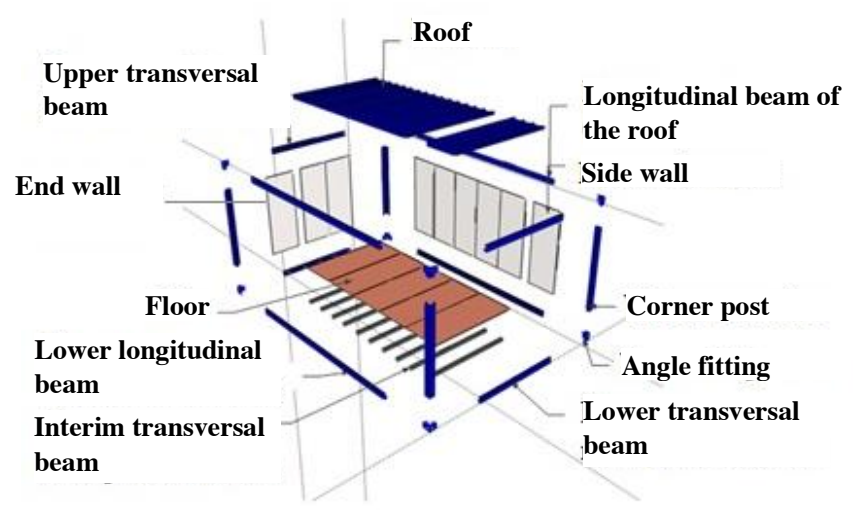

Fig. 1. Freight container design.

Let's review the lading anchors in details. For the general purpose containers, the lading anchors are not obligatory, but if any, they should meet the mandatory requirements [10].

Depending on the type of container, the mandatory number of lading anchors in the container base (see column 6 in Table 1).

The number of lading anchors not arranged in the container base is not established by the regulatory documents. The universal containers with such anchors additionally provided 


\section{ESMGT 2021}

on the longitudinal beams of the roof (Fig. 2) have become most popular, and those on the side walls have become more rare.

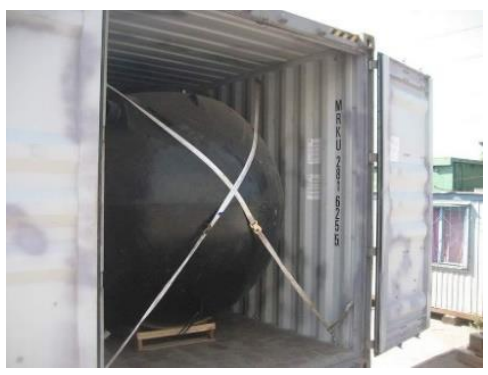

Fig. 2. Use of fittings on the lower and upper longitudinal beams to secure cargo in the universal container.

Standard [10] sets forth the allowed loads on the design elements of the universal containers given in Table 2 .

Table 2. Allowed loads on the design elements of the universal containers.

\begin{tabular}{|l|c|}
\hline \multicolumn{1}{|c|}{ Loaded element; kind of load } & Load value \\
\hline Evenly distributed side wall load & $0.6 \mathrm{P} *(\mathrm{tf})$ \\
\hline Evenly distributed end wall load & $0.4 \mathrm{P}(\mathrm{tf})$ \\
\hline $\begin{array}{l}\text { Lading anchors: } \\
\text { - in the container base }\end{array}$ & $10 \mathrm{kN}(1.0 \mathrm{tf})$ in all directions \\
- in the side walls and upper beams & $5 \mathrm{kN}(0.5 \mathrm{tf})$ in all directions \\
\hline $\mathrm{P}$ - container capacity
\end{tabular}

We consider that the normative strength parameters of the universal containers must be taken into account in calculations for justification of placement and securing of cargoes in the universal containers.

Let's analyse the existing transportation conditions of the universal multi-tonnage containers on platforms. These requirements are set forth by Chapter 9 of the Technical Conditions $[2,3]$.

Currently, the fitting platforms with the loading length of 40, 60, 80 feet to place from one to four 20 -foot containers, one or two 40 -foot containers, are used by railways for container transportation (Table 3).

Table 3. Kinds of transportation platforms for universal multi-tonnage containers and their characteristics.

\begin{tabular}{|c|c|c|c|c|}
\hline $\begin{array}{c}\text { Kinds of } \\
\text { fitting } \\
\text { platforms }\end{array}$ & Type of rolling stock & $\begin{array}{c}\text { Wagon length } \\
\text { over pulling } \\
\text { faces of } \\
\text { couplers, } \mathrm{m}\end{array}$ & $\begin{array}{c}\text { Type of } \\
\text { container }\end{array}$ & $\begin{array}{c}\text { Number of containers on } \\
\text { the wagon, cont. }\end{array}$ \\
\hline 40 -foot & $\begin{array}{c}\text { Platform with base } \\
9720 \mathrm{~mm}\end{array}$ & 14.62 & 20 -foot & 2 \\
\cline { 3 - 5 } & & & 40 -foot & 1
\end{tabular}


Table 3. Continued

\begin{tabular}{|c|c|c|c|c|}
\hline \multirow{2}{*}{60 -foot } & \multirow{2}{*}{$\begin{array}{c}\text { Platform with base } \\
13900 \mathrm{~mm}, \\
14400 \mathrm{~mm}, \\
14720 \mathrm{~mm}\end{array}$} & \multirow[t]{2}{*}{19.62} & 20 -foot & $1-3$ \\
\hline & & & 40 -foot & 1 \\
\hline \multirow{2}{*}{80 -foot } & \multirow{2}{*}{$\begin{array}{l}\text { Platform with base } \\
18500 \mathrm{~mm} \text { and more }\end{array}$} & \multirow[t]{2}{*}{25.69} & 20 -foot & $2-4$ \\
\hline & & & 40 -foot & $1-2$ \\
\hline
\end{tabular}

It is commonly known [11] that the transversal and vertical inertia forces act simultaneously. They are caused by oscillations of the moving wagon, such as chattering, pitching, swaying, side roll, hunting [11]. At this, the transversal and vertical accelerations increase along the wagon from the center to the ends.

Nevertheless, when justifying the technologies of placement and securing of cargoes in the universal containers according to the existing method, the transversal and vertical forces are calculated according to the standard formulas of the Technical Conditions $[2,3]$ that do not consider the conditions of container placement on the platform, as well as its parameters (wagon base).

To correct the method provided for in the Technical Conditions [2] in terms of specified calculation of the transversal and vertical inertia forces acting on the cargo in the container during transportation, let's consider the worst options (Fig. 3, 4), with the center of gravity of the end 20- and 40-foot containers to be maximum remote from the transverse axis of the longest platform (80-foot).

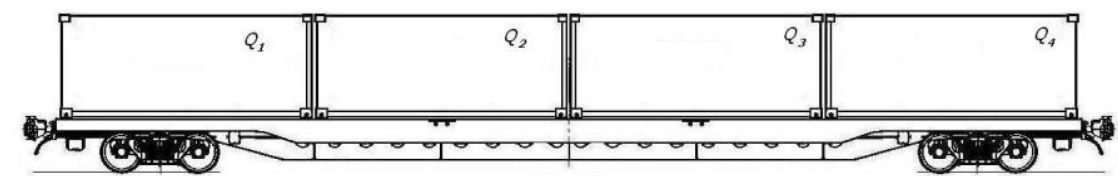

Fig. 3. The worst design option of arrangement of the 20 -foot containers on the 80 -foot platform.

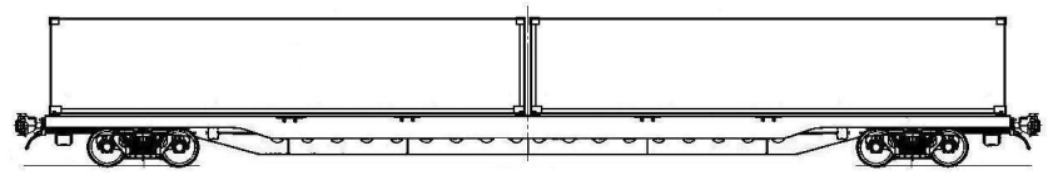

Fig. 4. The worst design option of arrangement of the 40 -foot containers on the 80 -foot platform.

According to [2], the transversal inertia force is determined according to the formula, assuming $a_{\mathrm{t}}$ is the specific transversal inertia force per $1 \mathrm{t}$ of cargo weight, $\mathrm{tf} / \mathrm{t}, Q_{\mathrm{c}}$ is the total cargo weight in the container, $t f$ :

$$
F_{\mathrm{t}}=a_{\mathrm{t}} Q_{\mathrm{c}}
$$

The specific transversal inertia force is calculated according to the following formula considering the distance from the center of gravity of cargo in the container that is maximum remote from the transverse axis of the wagon, where $l_{\mathrm{w}}$ is the wagon base $(\mathrm{mm})$, $l_{\mathrm{cc}}$ is the distance from the center of gravity of cargo in the container to the vertical plane passing through the transverse axis of the wagon $(\mathrm{mm})$ :

$$
a_{\mathrm{t}}=0,33+\left(0,44 / l_{\mathrm{w}}\right) l_{\mathrm{cc}}
$$


Let's calculate $l_{\mathrm{cc}}$ :

$$
l_{\mathrm{cc}}=l_{\mathrm{c}}+l_{\mathrm{s}}
$$

In formula (3), the following symbols are used: $l_{\mathrm{c}}$ is the distance from the center of gravity that is maximum remote from the transverse axis of the wagon of the container to the vertical plane passing through the transverse axis of the wagon $(\mathrm{mm}), l_{\mathrm{s}}$ is the distance from the center of gravity that is maximum remote from the transverse axis of the wagon of the container to the center of gravity of cargo in the container (to be calculated according to the method provided in the Technical Conditions [3, 4]), this value is taken with sign "+" if the center of gravity of cargo is to the right of the center of gravity of the container, and with sign "-" in other case.

To determine the vertical inertia force, the following formula is used:

$$
F_{\mathrm{v}}=a_{\mathrm{v}} Q_{\mathrm{c}}
$$

We will calculate the specific vertical inertia force per 1 ton of the cargo weight $a_{v}(t f / t)$ from the expression, where $k$ is the coefficient equal to $5 \cdot 10^{-6}$ :

$$
a_{\mathrm{v}}=0,25+k l_{\mathrm{cc}}+2,14 / Q_{\mathrm{c}}
$$

To calculate the distance $\ell_{\text {грк }}$, let's consider the distances between the fitting stops of the 80 -foot platforms (Fig.5).

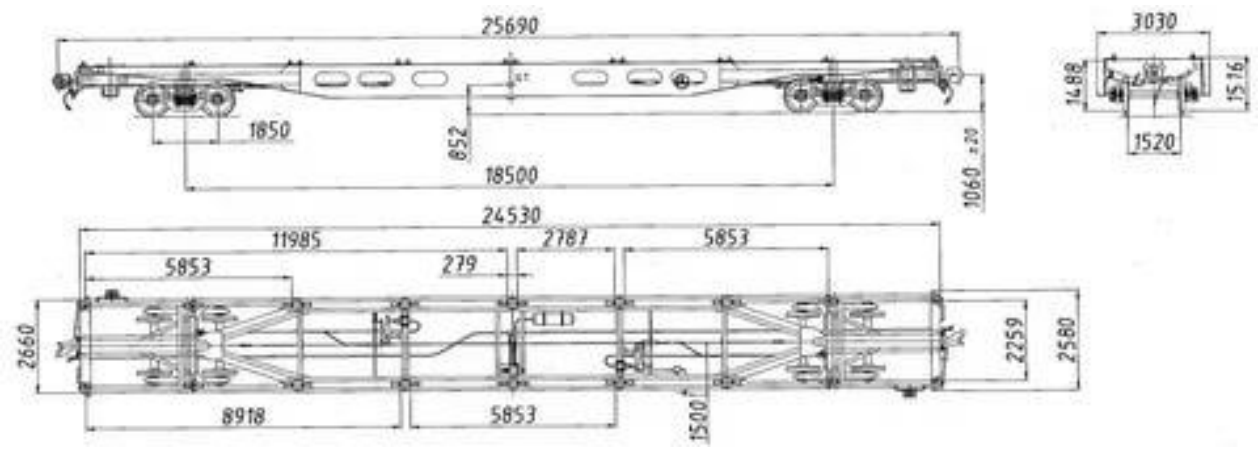

Fig. 5. Arrangement of fitting stops on the 80 -foot platforms.

Therefore, for arrangement of the 20-foot multi-tonnage containers (Fig. 3), the distance is $l_{\mathrm{c}}=1.5 \mathrm{x}(279+5853)=9198 \mathrm{~mm}$.

Therefore, for arrangement of the 40-foot multi-tonnage containers (Fig. 4), the distance is $l_{\mathrm{c}}=0.5 \times 279+5853 \approx 5993 \mathrm{~mm}$.

It should be noted that the axial inertia forces for cargo in the container are calculated according to the method provided for in the Technical Conditions [2, 3].

As an example, let's provide the results of comparative calculations for justification of placement and securing of timber cargoes with the weight of 15 ton in the 20 -foot multitonnage containers according to the method provided for in the Technical Conditions and the offered method (Table 4) that were received with the use of the software package MathCAD. 
Table 4. Calculation results according to the existing and offered method.

\begin{tabular}{|c|c|c|}
\hline Parameter & $\begin{array}{c}\text { According to the method } \\
\text { provided for in the Technical } \\
\text { Conditions [2] }\end{array}$ & According to the offered method \\
\hline$Q_{\mathrm{c}}, \mathrm{tf}$ & 15 & 15 \\
\hline$a_{\mathrm{l}}, \mathrm{tf} / \mathrm{t}$ & 1.15 & 1.15 \\
\hline$F_{\mathrm{l}}, \mathrm{tf}$ & 17.25 & 17.25 \\
\hline$l_{\mathrm{w}}, \mathrm{mm}$ & 19000 & 19000 \\
\hline$l_{\mathrm{c}, \mathrm{mm}}$ & 600 & 9198 \\
\hline$l_{\mathrm{s}, \mathrm{mm}}$ & 0 & 600 \\
\hline$l_{\mathrm{cc}}, \mathrm{mm}$ & 0 & 9798 \\
\hline$a_{\mathrm{t}}, \mathrm{tf} / \mathrm{t}$ & 0.344 & 0.557 \\
\hline$F_{\mathrm{t}}, \mathrm{tf}$ & 5.16 & 8.35 \\
\hline$a_{\mathrm{v}}, \mathrm{tf} / \mathrm{t}$ & 0.396 & 5.935 \\
\hline$F_{\mathrm{v}}, \mathrm{tf}$ & 0.442 & 6.62 \\
\hline$F_{\mathrm{ft}}, \mathrm{tf}$ & 4.08 & 3.77 \\
\hline$F_{\mathrm{fl}}, \mathrm{tf}$ & 6.75 & 6.75 \\
\hline$\Delta F_{\mathrm{t}}, \mathrm{tf}$ & 2.37 & 6.67 \\
\hline$\Delta F_{1}, \mathrm{tf}$ & 10.5 & 10.5 \\
\hline
\end{tabular}

The analysis of the performed calculations shows that the transverse force $\Delta F_{\mathrm{t}}$ acting on cargo in the container according to the specified method exceeds the similar force calculated according to the method provided for in the Technical Conditions [2] by almost 3 times. With certain initial data, such difference can lead to exceedance of the normative loads to the container side walls and risk to safety of movement.

Let's provide the design-based justification of load borne by the container side walls for the above example. According to Table 2 , for the 20 -foot container, the allowed load will make $16.85 \mathrm{tf}(0.6 P=0.6 \times 28.08=16.85 \mathrm{tf})$. Therefore, the transverse force value received by means of two methods in Table 4 does not exceed the allowed value.

The maximum longitudinal load compensated by the container end wall (door) according to Table 2 makes 11.23 tf $(0.4 P=0.4 \times 28.08)$. The axial force of 10.5 tf does not exceed the allowed load on the container end wall (door).

The importance of checking calculation of loads in the axial direction should be particularly noted. For this example, transportation of cargo over 15 tons will lead to exceedance of the allowed loads on the container end walls (door) and threaten safety of movement.

\section{Conclusions}

1. It is found out that the absence of the approved method for justification of securing of cargo in containers during railway transportation causes difficulties for consignors in choosing rational methods for the placement and securing of cargoes in containers and, of course, affects the sustainable development of railway transportation in containers and the transportation safety.

2. The conducted design analysis of the universal containers made it possible to identify the basic elements the inertia forces of the cargo are transferred to, they are the side and end walls, lading anchors (in the container base, on the longitudinal beam of the roof, on the side walls).

3. The main normative loads on the container elements the inertia forces of the cargo are transferred to have been identified. These values determine the cargo weight that can be loaded into the container and should be taken into account for designbased justification of placement and securing of cargo in the universal containers. 
4. The method for calculation of the transversal and vertical inertia forces acting on the cargo in the container during transportation considering the principles of placement of containers on the wagon and cargo in the container has been offered.

5. The conducted comparative analysis of calculations for justification of placement and securing cargoes in the universal containers according to the method provided for in the Technical Conditions and the offered method showed that the value of the transverse force acting on the cargo in transit received from the offered method considerably (by 3 times) exceeded the similar force received from the formulas provided for in the Technical Conditions. With certain initial data, such difference can lead to exceedance of the normative loads to the container side walls and risk to safety of movement.

6. The importance of $f$ checking calculation of loads in the axial direction has been noted. The calculated cargo weight values can lead to exceedance of the allowed loads on the container end walls and threaten safety of movement.

\section{References}

1. Russian Railwayshttps://company.rzd.ru/

2. JSC "Codex", http://docs.cntd.ru/

3. Trading house "BMZ" Moscow, https://www.bmzm.ru/

4. S. Suvorova, E. Naumova, I. Scherbanyuk, I., IOP Conference Series: Materials Science and Engineering, 918(1), 012044 (2020)

5. A. Egorov, N. Pilipchuk, I. Khmelev, V. Shatokhin, A. Kovkin, IOP Conference Series: Materials Science and Engineering, 698(6), 066050 (2019)

6. S. Aksentijević, E. Tijan, M. Jović, N. Munitić, 43rd International Convention on Information, Communication and Electronic Technology, 20179309, 9 (2020)

7. Kh. T. Turanov, A.A.Gordienko, Technologies of placement and securing cargoes in cars (Ural State University of Railway transport Press, Ekaterinburg, 2020)

8. Kh.T.Turanov, A.A.Gordienko, S.A.Sitnikov, Science and Technology in Transport, 2, 8 (2014)

9. Information portal "LABOR PROTECTION IN RUSSIA", https://ohranatruda.ru/

10. ISO, https://www.iso.org/

11. Kh.T.Turanov, Interaction of open rolling stock and solid cargo (Educational and Methodological Center for Education in Railway Transport, Moscow, 2011) 